\title{
Left atrial appendage ligation with single transthoracic port assistance: a study of survival assessment in a porcine model (with videos)
}

João Moreira-Pinto, MD, ${ }^{1,2,3}$ Aníbal Ferreira, MD, ${ }^{1,2,4}$ Alice Miranda, DVM, ${ }^{1,2}$ Carla Rolanda, MD, PhD, ${ }^{1,2,4}$ Jorge Correia-Pinto, $\mathrm{MD}, \mathbf{P h D}^{1,2,5}$

Braga, Portugal

Background: Left atrial appendage (LAA) exclusion is a well-known procedure for the prevention of stroke in high-risk patients with atrial fibrillation and contraindication to long-term oral anticoagulant therapy.

Objective: To evaluate a natural orifice transluminal endoscopic surgery (NOTES) approach for LAA ligation.

Design: In 4 acute and 6 survival pigs, we performed LAA by using a forward-viewing, single-channel gastroscope and an operative thoracoscope with a 3-mm working channel (introduced through an 8-mm single transthoracic port).

Setting: Animal laboratory.

Interventions: The gastroscope was introduced in the thoracic cavity through an esophageal submucosal tunnel. An end loop introduced through the gastroscope was used to legate the LAA. In the survival experiments, the esophageal mucosa was closed using hemoclips.

Main Outcome Measurements: The time, safety, and feasibility of the procedure were recorded. In the survival experiments, endoscopy and postmortem examination were performed on postoperative day 14 .

Results: Creation of a submucosal tunnel and esophagotomy were safely performed in all animals without incidents. The mean time for esophagotomy was $17.0 \pm 6.3$ minutes. Pericardial dissection and LAA ligation were performed in all animals but 1. The mean time for LAA ligation was $34.4 \pm 19.1$ minutes. No adverse events occurred during the survival period. Endoscopy showed complete esophageal closure. Postmortem examination revealed pleural adhesions on the site of pericardial dissection, and the LAA was fibrotic with the endoloop in place.

Limitations: Animal study.

Conclusions: LAA ligation with single transthoracic trocar assistance is feasible and may be an alternative to anticoagulant therapy or to permanent intracardiac implants in patients with atrial fibrillation. (Gastrointest Endosc 2012;75:1055-61.)

Abbreviations: AF, atrial fibrillation; IM, intramuscularly; LAA, left atrial appendage; NOTES, natural orifice transluminal endoscopic surgery.

DISCLOSURE: The following author disclosed a financial relationship relevant to this publication: Dr Correia-Pinto, consultant to Karl Storz. The other authors disclosed no financial relationships relevant to this publication. This project was funded by the Grants FCT project PTDC/ SAU-OSM/105578/2008.

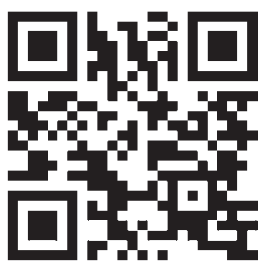

This video can be viewed directly from the GIE website or by using the QR code and your mobile device. Download a free $Q R$ code scanner by searching "QR Scanner" in your mobile device's app store.
Copyright $\odot 2012$ by the American Society for Gastrointestinal Endoscopy 0016-5107/\$36.00

doi:10.1016/j.gie.2011.12.018

Received October 13, 2011. Accepted December 16, 2011.

Current affiliations: Life and Health Sciences Research Institute (1), School of Health Sciences, University of Minho, Braga, Portugal; ICVS/3Bs - PT Government Associate Laboratory (2), Braga/Guimarães, Portugal; Department of Pediatric Surgery (3), Centro Hospitalar do Porto, Porto, Portugal; Departments of Gastroenterology (4) and Pediatric Surgery (5), Hospital de Braga, Braga, Portugal.

Reprint requests: Jorge Correia-Pinto, MD, PhD, Instituto de Ciências da Vida e Saúde, Escola de Ciências da Saúde, Universidade do Minho, Campus de Gualtar, 4709-057 Braga, Portugal. 
Atrial fibrillation (AF) is the most common cardiac arrhythmia, affecting more than 6 million people worldwide. ${ }^{1}$ AF increases the risk of stroke by 4 - to 5 -fold in nonrheumatic patients ${ }^{2}$ and by 17 -fold in the setting of rheumatic mitral stenosis. ${ }^{3}$ It is responsible for $10 \%$ of all ischemic strokes and half of all cardioembolic strokes. ${ }^{4}$ Although anticoagulation therapy is effective, alternative means to avert the risk of stroke from thromboembolism are being studied because of the need for monitoring, the risk of bleeding complications, and the potential for drug interactions. ${ }^{5}$

Several studies found a predilection for thrombus to form in the left atrial appendage (LAA) in patients with AF because of the increase in its size and flow pattern alteration. ${ }^{6}$ Thus, several methods to occlude the LAA have been assessed to decrease stroke burden. Open-surgery LAA ligation has been widely assessed for feasibility, safety, and efficacy in stroke prevention. ${ }^{7}$ Thoracoscopic LAA ligation has been described with similar results. ${ }^{8}$ In 2002, Sievert et $\mathrm{al}^{9}$ presented the technique for LAA occlusion using a percutaneous endovascular device that delivers an expandable cage into the LAA, preventing blood to flow inside it. Since then, several percutaneous devices have been developed and are currently being tried. ${ }^{5} \mathrm{Al}-$ though these percutaneous devices show promising results, several possible complications remain (pericardial effusion, air embolism, device migration, pseudoaneurysm, infection, and device thrombus formation). There are also some limitations (LAA size and variable anatomy) that demand, in specific cases (eg, size disproportion or distorted anatomy of LAA), the development of alternative surgical techniques for LAA ligation. ${ }^{10}$

With the recent developments in natural orifice transluminal endoscopic surgery (NOTES), one should be aware that new approaches to the thorax are emerging as alternatives to the classic thoracoscopic surgery. In 2007, Sumiyama et $\mathrm{al}^{11}$ proposed a transesophageal access to the thoracic cavity. Since then, transesophageal NOTES has been tested for several simple thoracic procedures in a porcine model. ${ }^{12-18}$ Moreover, EUS and FNA of transesophageal lesions are established diagnostic techniques in gastroenterology and are now also used for therapeutic purposes. With the proximity of the heart to the esophagus and the utility of the diagnostic technique of transesophageal echocardiography in mind, Fritcher-Ravens et al ${ }^{19}$ tested introducing a needle through the esophagus wall and the posterior cardiac wall into the left atrium and beyond, as far as the aortic valve, with success in a porcine model. Considering transesophageal access for performing cardiac surgery, surgeons can see some hurdles. First, the possible mechanical abrasion of and trauma to surrounding structures while performing an inside-out esophagotomy. Moreover, an ineffective esophagotomy closure can be devastating, with serious infectious complications. Finally, tissue manipulation and suturing can be challenging when using flexible parallel instruments from the con-

\section{Take-home Message}

- Transesophageal natural orifice transluminal endoscopic surgery with single transthoracic assistance (with or without transesophageal US monitoring) might be the key to human translation of simple thoracic procedures.

- Transesophageal left atrial appendage might be a good alternative to percutaneous endovascular techniques.

ventional gastroscope. Rolanda et $\mathrm{al}^{20}$ recently proposed the combination of a single transthoracic trocar with transesophageal NOTES to increase the safety and feasibility of more complex procedures.

We hypothesized that thoracic NOTES might be indicated in ultraminimally invasive LAA ligation, independently of the size or distorted anatomy of LAA. Thus, we designed this research protocol to assess the feasibility and reliability of peroral transesophageal LAA ligation with the assistance of a single transthoracic trocar.

\section{MATERIAL AND METHODS}

\section{Study design}

Ten female pigs (Sus scrofus domesticus) weighing 25 to $35 \mathrm{~kg}$ were used to perform transesophageal LAA ligation with the assistance of a single transthoracic trocar. Ten consecutive in vivo experiments were undertaken ( 4 acute and the last 6 animals for survival assessment). All surgical endoscopic and thoracoscopic procedures were recorded. Vital signs and physiological parameters were monitored during the experiment. The procedure time was recorded as well as difficulties and complications at each step of the procedure. The animals in the survival group were monitored for 14 days. Endoscopic examination and necropsy were performed in all animals at the end of the protocol (after the procedure in the acute animals and after the survival animals were killed). This study was approved by the ethical review board of Minho University (Braga, Portugal).

\section{Pig preparation}

All procedures were performed with the animals under general anesthesia with endotracheal intubation and mechanical ventilation (Fig. 1). The pigs had no food (8 hours) or water ( 4 hours) before the surgery. The pigs were premedicated with a combination of azaperone ( 4 $\mathrm{mg} / \mathrm{kg}$, intramuscularly [IM]), midazolam (1 mg/kg, IM), and atropine $(0.05 \mathrm{mg} / \mathrm{kg}, \mathrm{IM})$. Anesthesia was induced with propofol (6 mg/kg, intravenously) and maintained with continuous propofol infusion $(20 \mathrm{mg} / \mathrm{kg} / \mathrm{h}$, intravenously) and buprenorphine $(0.05 \mathrm{mg} / \mathrm{kg}, \mathrm{IM})$.

\section{Surgical technique}

The main steps of the procedure described here are schematically illustrated in Figure 2. The pig was placed in 


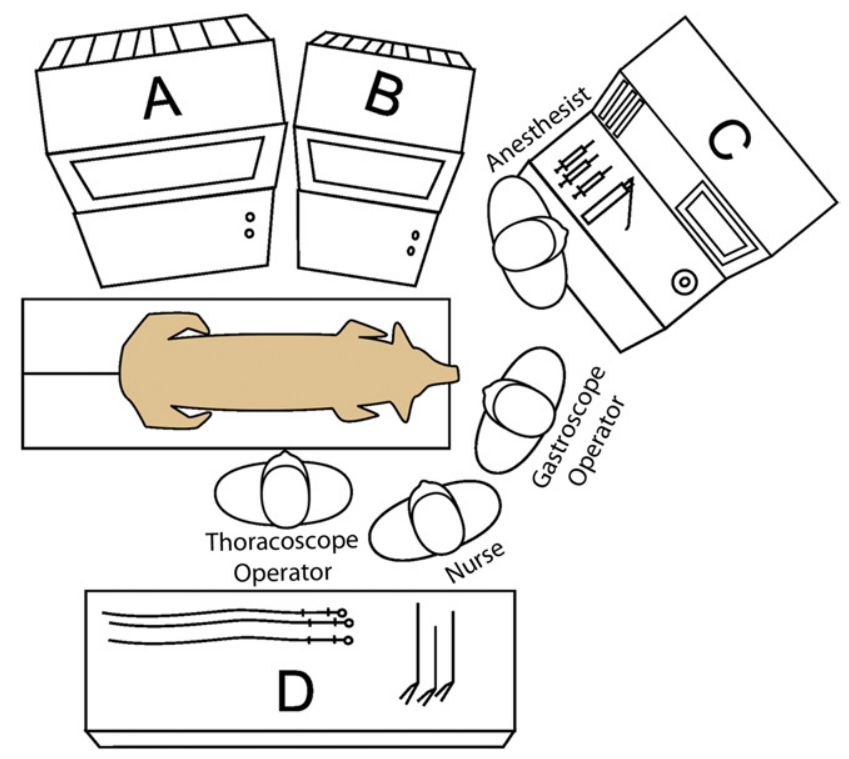

Figure 1. Room ergonomics. A, Thoracoscope monitor. B, gastroscope monitor. C, Ventilator. D, Back table for equipment.

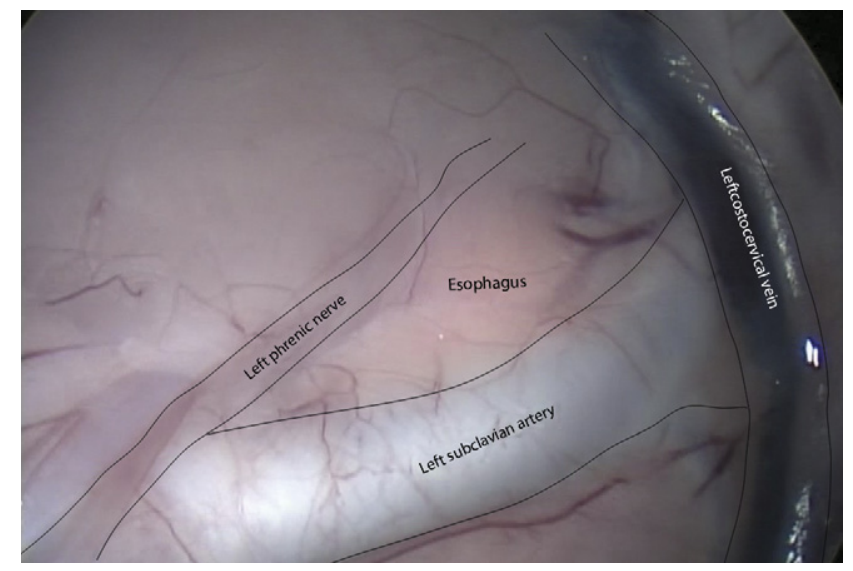

Figure 2. Thoracoscopic anatomy of the esophagotomy site.

the dorsal decubitus position. An 8-mm trocar (C0Q61, Kii Shielded Bladed Access System; Applied Medical, Rancho Santa Margarita, Calif) was inserted in the fourth intercostal space in the left anterior axillary line. $\mathrm{CO}_{2}$ was inflated through the transthoracic trocar, and pressure was maintained up to $6 \mathrm{~mm} \mathrm{Hg}$. An operative thoracoscope with a 3-mm working channel (Hopkins Wide-Angle Straight Forward Telescope 6 Degrees, 27092AMA; Karl Storz, Tuttlingen, Germany) was introduced through the trocar. By using a rigid dissector (30310MLG; Karl Storz), we dissected the upper mediastinum and identified the esophagus, with the help of gastroscope movements (inside the esophagus) and transillumination, between the left phrenic nerve, the left costocervical vein, and the left subclavian artery (Fig. 3).

A forward-viewing, single-channel gastroscope (13801PKS; Karl Storz) was advanced into the esophagus, identifying the position of the thoracoscope and the esophagotomy site. Five milliliters of saline solution were injected into the
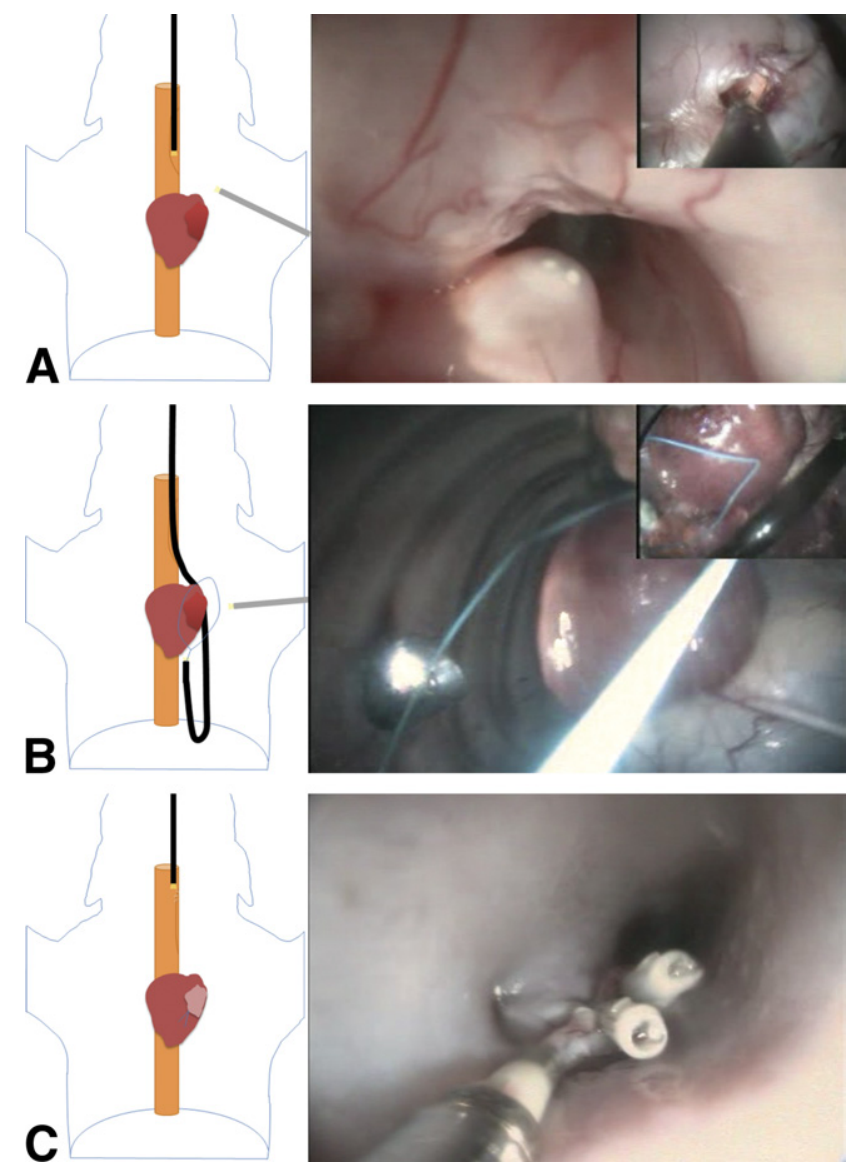

Figure 3. Steps for transesophageal left atrial appendage ligation. Main image represents gastroscopic view, and insets $(\mathbf{A}, \mathbf{B})$ represent thoracoscopic view. A, Gastroscope going through the submucosal tunnel and thoracoscope showing the exact site for esophagotomy. B, Endoloop going through the gastroscope working channel and thoracoscopic positioning of the LAA inside it. C, Closing the mucosal incision of the esophagus with 3 hemoclips.

submucosa $8 \mathrm{~cm}$ proximal to the esophagotomy position, by using an injection needle (110231-01; Karl Storz), and a 1 -cm longitudinal incision was made in the mucosa using a needle-knife (KD-11Q-1; Olympus, Tokyo, Japan) through the gastroscope working channel. Then an 8- to 9-cm long submucosal tunnel was created by blunt dissection. Esophagotomy was performed in the distal part of the submucosal tunnel (in the upper third of the esophagus). All transesophageal procedures were performed under gastroscopic and thoracoscopic image control.

The pericardium was incised above the LAA, avoiding the left phrenic nerve, using a rigid grasper (27290K; Karl Storz) inserted through the thoracoscope working channel for traction and the needle-knife with cautery through the gastroscope for cutting. To further dissect the pericardium, we inverted the positions. A flexible grasper (11252MX; Karl Storz) and rigid 3-mm scissors (30310MW; Karl Storz) were inserted through the working channels of the gastroscope and thoracoscope, respectively. 
TABLE 1. Results of 4 acute and 6 survival experiments

\begin{tabular}{|c|c|c|c|c|}
\hline Experiment & $\begin{array}{l}\text { Esophagotomy: } \min , \\
\text { complications }\end{array}$ & $\begin{array}{l}\text { Pericardium incision and } \\
\text { LAA ligation: min, } \\
\text { complications }\end{array}$ & $\begin{array}{l}\text { Esophagotomy closure: } \mathrm{min}, \\
\text { complications }\end{array}$ & Acute vs survival \\
\hline 1 & 20 & 25 & - & Acute \\
\hline 2 & 25 & 20 & - & Acute \\
\hline 3 & $\begin{array}{l}\text { 30, small thymus hemorrhage during } \\
\text { pleural dissection solved without the } \\
\text { need for coagulation }\end{array}$ & $\begin{array}{l}\text { 30, small LAA wall hemorrhage } \\
\text { during manipulation solved } \\
\text { without the need for } \\
\text { coagulation }\end{array}$ & - & Acute \\
\hline 4 & 15 & $\begin{array}{l}\text {-, iatrogenic rupture of LAA } \\
\text { because of traumatic grasper } \\
\text { misuse }\end{array}$ & - & $\begin{array}{l}\text { Acute (interrupted } \\
\text { at } 35 \mathrm{~min} \text { ) }\end{array}$ \\
\hline 5 & 15 & 30 & 5 & Survival (14 d) \\
\hline 6 & 15 & $\begin{array}{l}45, \text { small LAA wall hemorrhage } \\
\text { during manipulation, solved } \\
\text { without the need for } \\
\text { coagulation }\end{array}$ & 15 & Survival (14 d) \\
\hline 7 & 10 & $\begin{array}{l}60 \text {, small LAA wall hemorrhage } \\
\text { during manipulation, solved } \\
\text { without the need for } \\
\text { coagulation }\end{array}$ & 15 & Survival (14 d) \\
\hline 8 & 15 & 5 & 5 & Survival (14 d) \\
\hline 9 & 10 & 30 & 10 & Survival (14 d) \\
\hline 10 & 15 & $\begin{array}{l}65 \text {, incomplete LAA ligation } \\
\text { because of previous pericardial } \\
\text { adhesions }\end{array}$ & 10 & Survival (14 d) \\
\hline
\end{tabular}

$L A A$, Left atrial appendage; - , not available.

After delimiting and externalizing the LAA by using a rigid atraumatic grasper (30310ONG; Karl Storz) introduced through the thoracoscope, the LAA was ligated by using a nylon endoloop (disposable ligation device HX400U-30; Olympus) introduced through the gastroscope and positioned with the help of a thoracoscopic grasper.

In the survival group, in addition to the surgical procedure described, the esophageal mucosa was closed at the proximal edge of the submucosal tunnel by using 3 flexible hemoclips (EZ Clip HX-110LR; Olympus). At the end of the procedure, the pericardium was left open, and the pneumothorax was drained by using a thoracic tube introduced through the transthoracic trocar. No drain was left in place after the intervention. The trocar skin incision was sutured with 2 nonabsorbable independent stitches.

\section{Postoperative care (survival group)}

At the end of the surgical intervention, all animals received a single dose of buprenorphine $(0.05 \mathrm{mg} / \mathrm{kg}, \mathrm{IM})$ and meloxicam $(0.4 \mathrm{mg} / \mathrm{kg}, \mathrm{IM})$. Antibiotic ceftiofur hydrochloride $(5 \mathrm{mg} / \mathrm{kg}$, IM) was repeated at 24-hour intervals for 3 consecutive days. A regular diet was resumed 8 hours after surgery. The animals were closely monitored for any signs of postoperative complications, distress, behavior changes, anorexia, or weight loss. After the follow-up period, the animals were anesthetized for endoscopic examination. Then they were killed, and necropsy was performed to check for LAA complete ligation, healing of the esophagotomy, and signs of cardiac or pulmonary complications.

\section{RESULTS}

The overall results of our study are summarized in Table 1 . Dorsal decubitus and the $\mathrm{CO}_{2}$ insufflation permitted good visualization of the heart and the pericardium up to the apex. Coordinating the images from the thoracoscope and gastroscope allowed us to determine the ideal site for esophagotomy. Submucosal tunnel creation and esophagotomy were performed safely without incident in all animals (Fig. 3A; Video 1, available online at www. giejournal.org). The mean time to perform the esophagotomy was $17.0 \pm 6.3$ minutes.

Pericardial opening and complete LAA ligation were performed without significant problems in all but 2 animals (Fig. 3B; Video 2, available online at www.giejournal.org). Liga- 
tion was achieved by coordinating both thoracoscopic and gastroscopic images and instruments with minimal mobilization of the LAA. As the endoloop was introduced from the apex by using the gastroscope in a retroflexed position, the atraumatic grasper through the thoracoscope adjusted the upper part of the LAA inside the loop. In experiment 4 , misuse of the conventional grasper to manipulate LAA caused tearing of the LAA. The hemorrhage was controllable by grasping the perforation with the atraumatic grasper, but the animal died, and we terminated the experiment. In the last experiment, pericardial adhesions from a previous infection did not permit a good dissection of the LAA, and only partial ligation was achieved. The mean time for LAA ligation was $34.4 \pm 19.1$ minutes.

The instruments entering through both the gastroscope and thoracoscope created a triangulation very similar to the one experienced with the exclusively thoracoscopic approach. The flexible endoscope had good access to all aspects of the heart by using a direct position to reach the base of the heart and retroflexion for its apex. Moreover, a flexible gastroscope was useful in showing some parts of the thoracic cavity that could not be visualized with the 6-degree optic of the operative thoracoscope, ie, the lateral thoracic wall and the entire diaphragm.

With exception of the acute experiment that was terminated because of LAA rupture, all of the other animals were kept alive until the end of the experiment. LAA ligation was verified on necropsy.

In the survival group, the esophageal mucosa was closed by using endoscopic clips (Fig. 3C; Video 3, available online at www.giejournal.org), and the thoracotomy was sutured after pneumothorax drainage. The mean time to close was $10.0 \pm 4.5$ minutes. The total mean operating time in the survival group was $62.5 \pm 25.1$ minutes. All 6 animals in the survival group lived for 14 days. After recovering from anesthesia, the pigs tolerated a regular diet started 8 hours after surgery and ambulated freely, exhibiting normal behavior. No adverse event occurred during the survival period. Endoscopic examination before killing revealed complete esophageal closure in all animals (Fig. 4). No esophageal strictures were found. Postmortem examination revealed pleural adhesions on the site of pericardial dissection, and the LAA was fibrotic with the nylon endoloop in place (Fig. 5). There were no signs of infection in the ipsi- or contralateral pleural space and lung parenchyma.

\section{DISCUSSION}

LAA ligation is a well-known procedure for the prevention of strokes in high-risk patients with AF and a contraindication to long-term oral anticoagulant therapy. Open surgery is highly invasive and is only performed in patients requiring other cardiac surgery such as mitral valve surgery and maze procedures. ${ }^{5}$ Ligation of the LAA can also

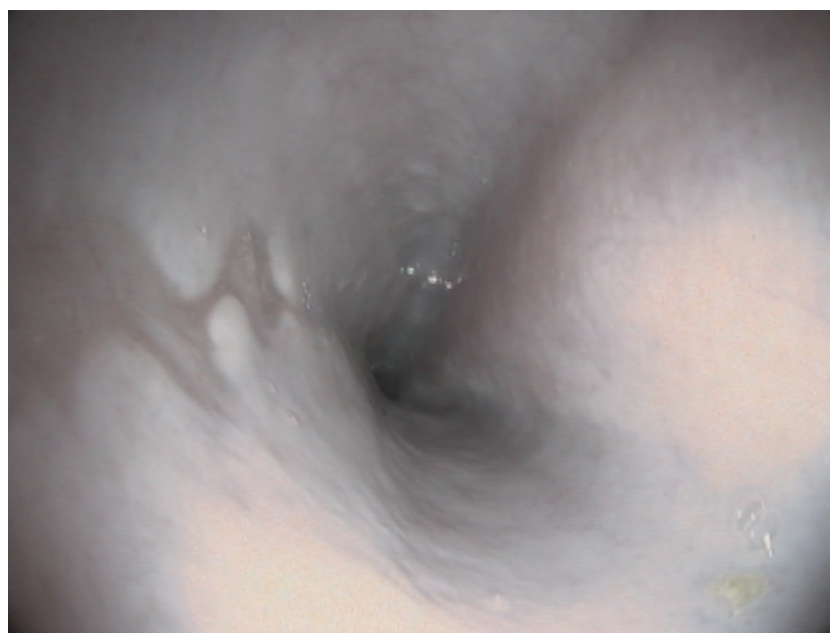

Figure 4. Esophageal mucosa scar 14 days postoperatively.
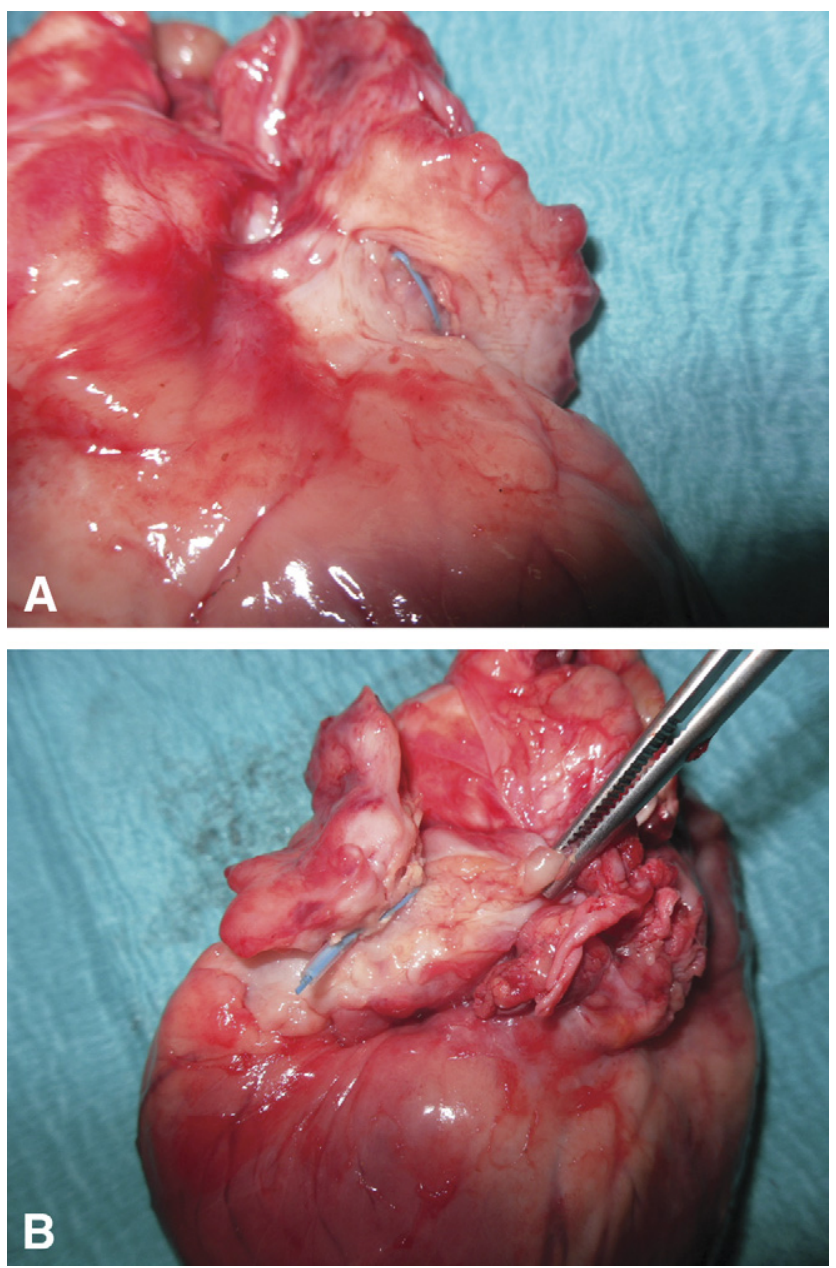

Figure 5. Heart view showing fibrotic left atrial appendage 14 days after ligation with the endoloop in place. A, Anterior view. B, Posterior view.

be performed thoracoscopically using an endoloop or stapling device with similar results. ${ }^{8}$

Recently, percutaneous catheter-based systems to occlude the LAA have been presented. The Amplatzer Septal 
occluder (AGA Medical Corporation, Golden Valley, Minn), which was originally described for patent foramen ovale or atrial septal defect closure, evolved into the Amplatzer Cardiac Plug (AGA Medical Corporation) and is currently being compared in a clinical trial.5,9 The PLAATO system (eV3 Inc, Plymouth, Minn) is a self-expanding nitinol cage coated with a polytetrafluoroethylene membrane that ensures endothelialization of the implant. ${ }^{21}$ The WATCHMAN Device (Atritech Inc, Plymouth, Minn) is also a self-expanding nitinol cage with a permeable polyester fabric covering the surface exposed to the left atrium. ${ }^{22}$ Although the first reports regarding percutaneous LAA occlusion show encouraging results, several possible complications still remain. ${ }^{5,20-22}$ These include air embolism, device embolization, perforation, device malposition, residual shunt, arrhythmia, infection, and thrombus formation on the device. ${ }^{23}$ Moreover, a large and distorted LAA cannot be completely occluded by endovascular devices. For these cases, alternative external LAA ligation techniques are being developed. In 2010, Lee et $\mathrm{al}^{10}$ reported a catheter-based LAA ligation technique using a minimally invasive surgical pericardial window created to access the pericardial space.

In the NOTES era, transesophageal endoscopic surgery is emerging as an alternative to the classic thoracoscopic surgery. The theoretical advantages of NOTES over open surgery and conventional thoracoscopy include decreased postoperative pain, reduction/elimination of general anesthesia, performance of procedures in an outpatient or even office setting, and possible cost reduction. Moreover, eliminating a skin incision avoids associated complications such as wound infections and hernias, and facilitates a shorter hospital stay, faster return to regular activity, improved cosmetic outcomes, and increased overall patient satisfaction. Recently, Rolanda et $\mathrm{al}^{20}$ introduced the concept of hybrid thoracic NOTES. By introducing a transthoracic trocar, the authors overcame some potential risks of the transesophageal approach, ie, blind esophagotomy creation, esophagotomy closure, thoracic drainage at the end of the procedure, and triangulating instruments. Transesophageal NOTES with single transthoracic assistance (with or without transesophageal US monitoring) might be the key to human translation of simple thoracic procedures, ie, LAA ligation.

As discussed earlier, the supine position allows gravity to provide good cardiac exposure with minimal handling. We did not need to retract the lung and that allowed us to focus the transthoracic instruments on the surgical procedure. We found the thoracic trocar very useful for $\mathrm{CO}_{2}$ inflation and for its pressure control. Also, the transthoracic trocar permitted the control of esophagotomy, performed from the inside-out of the esophagus, pointing out the exact place where it should be created, side and level, and avoiding lesions of arteries, veins, and nerves. Finally, when the procedure was completed, the trocar site was used for tube insertion and acute pleural drainage.
Combining 2 opposite sites, for insertion of the gastroscope and thoracoscope and respective instruments, we could obtain regular triangulation and countertraction that simulates the 2 hand movements of the surgeon. This promoted secure manipulation of tissues, careful dissection of the pericardium, and effective LAA ligation. The only LAA perforation that we had during the study was caused by the misuse of a traumatic grasper instead of using the atraumatic one that occurred in the first nonsurvival experiments. We did not experience this complication while using the atraumatic grasper. However, if this were to happen in a human, we believe that conversion to open surgery would be the best option. Again, the fact that we have a gastroscope inside the thorax may permit control of the hemorrhage by grasping the orifice or occluding it with a balloon, while an emergency sternotomy is performed. As mentioned earlier, the flexible endoscope inside the thorax allows visualization of the entire cavity including sites where rigid transthoracic endoscopes cannot reach, ie, the base and apex of the heart, identifying the limits of the LAA neck, even in large distorted ones.

Regarding the esophagotomy technique, various solutions for endoscopic esophagotomy closure have been suggested. Opening the muscular layer after a submucosal tunnel is created may not even require closing the mucosa. 9,16 We opted to close the mucosa with clips, and this technique was found to be reliable and quite effective in all of our survival experiments. Mediastinal and lung infection could be of some concern. The submucosal tunnel before esophagotomy creates a valve system that collapses as soon as the procedure is completed. As shown in our experiments, combining the esophageal submucosal tunnel with antibiotic prophylaxis is enough to avoid any type of infection.

Follow-up transesophageal US studies have found that surgical LAA occlusion is incomplete in between one third to one half of cases in patients undergoing LAA ligation via open surgery. ${ }^{7,25}$ In these studies, either regular nonabsorbable suture or staplers were used. None of these studies used a nylon endoloop for LAA ligation. In our study, necropsy revealed complete LAA ligation in all acute experiments, and full ligation with fibrotic LAA in all but 1 of the survival studies. However, as reported earlier, previous pericardial adhesions (eg, caused by previous thoracic intervention) might be a limiting factor for LAA dissection and full ligation when using our technique.

The animal model certainly is a limitation of our study, although the cardiac porcine anatomy is very similar to that of humans. Even so, survival experiments were essential to prove that transesophageal LAA ligation was not only feasible but reliable. Even without thoracic tube drainage, other than immediately after esophageal closure, all animals survived, with no thoracic sequelae except for minor local adhesions. Again, by using a hybrid NOTES approach we managed to perform LAA ligation safely and reliably. 
Our results proved that transesophageal NOTES, with the assistance of a single transthoracic trocar, can be used for cardiac procedures. We believe that transesophageal LAA could be indicated in patients with AF who do not want or cannot be on anticoagulant therapy. Transesophageal LAA might be a good alternative to percutaneous endovascular techniques, especially in patients who have large distorted LAA and are contraindicated for LAA occlusion with expandable devices or catheter-based ligation. ${ }^{24}$ Another advantage of transesophageal LAA ligation over percutaneous techniques is avoiding exposure of patients and health providers to unnecessary radiation from fluoroscopy. ${ }^{26}$

Finally, transesophageal LAA ligation can be the first step to more complex cardiac NOTES procedures, for instance, the maze procedure, which has been the criterion standard for the treatment of symptomatic drug-refractory $\mathrm{AF}$ and was recently performed by the thoracoscopic approach. ${ }^{27}$ Considering the described achievements, we propose that that our hybrid approach could be safely used in humans in what we believe to be a step forward in minimally invasive cardiac surgery. Clinical trials are necessary to determine whether this procedure should be generally applied and whether its potential benefits are actually superior to those of percutaneous techniques.

In conclusion, transesophageal LAA ligation by using single transthoracic trocar assistance is feasible and may represent a minimally invasive option for LAA ligation.

\section{REFERENCES}

1. Johnson WD, Ganjoo AK, Stone CD, et al. The left atrial appendage: our most lethal human attachment! Surgical implications. Eur J Cardiol Thorac Surg 2000;17:718-22.

2. Wolf PA, Abbott RD, Kannel WB. Atrial fibrillation as an independent risk factor for stroke: the Framingham Study. Stroke 1991;22:983-8.

3. Wolf PA, Dawber TR, Thomas HE, et al. Epidemiologic assessment of chronic atrial fibrillation and risk of stroke: the Framingham study. Neurology 1978;28:973-7.

4. Hart RG, Pearce LA, Rothbart RM, et al. Stroke with intermittent atrial fibrillation: incidence and predictors during aspirin therapy. J Am Coll Cardiol 2000;35:183-7.

5. Contractor T, Khasnis A. Left atrial appendage closure in atrial fibrillation: a world without anticoagulation? Cardiol Res Pract 2011:752808.

6. Garcia-Fernandez MA, Torrecilla EG, Román DS, et al. Left atrial appendage Doppler flow patterns: implications on thrombus formation. Am Heart J 1992;124:553-61.

7. Healey JS, Crystal E, Lamy A, et al. Left Atrial Appendage Occlusion Study (LAAOS): results of a randomized controlled pilot study of left atrial appendage obliteration during coronary bypass surgery in patients at risk for stroke. Am Heart J 2005;150:288-93.

8. Blackshear JL, Johnson WD, Odell JA, et al. Thoracoscopic extracardiac obliteration of the left atrial appendage for stroke risk reduction in atrial fibrillation. J Am Coll Cardiol 2003;42:1249-52.
9. Sievert $H$, Lesh MD, Trepels $T$, et al. Percutaneous left atrial appendage transcatheter occlusion to prevent stroke in high-risk patients with atrial fibrillation: early clinical experience. Circulation 2002;105:1887-9.

10. Lee RJ, Bartus K, Yakubov SJ. Catheter-based left atrial appendage (LAA) ligation for the prevention of embolic events arising from the LAA: initial experience in a canine model. Circ Cardiovasc Interv 2010;3:224-9.

11. Sumiyama K, Gostout CJ, Rajan E, et al. Transesophageal mediastinoscopy by submucosal endoscopy with mucosal flap safety valve technique. Gastrointest Endosc 2007;65:679-83.

12. Willingham FF, Gee DW, Lauwers GY, et al. Natural orifice transesophageal mediastinoscopy and thoracoscopy. Surg Endosc 2008;22:1042-7.

13. Fritscher-Ravens A, Patel K, Ghanbari A, et al. Natural orifice transluminal endoscopic surgery (NOTES) in the mediastinum: long-term survival animal experiments in transesophageal access, including minor surgical procedures. Endoscopy 2007;39:870-5.

14. Gee DW, Willingham FF, Lauwers GY, et al. Natural orifice transesophageal mediastinoscopy and thoracoscopy: a survival series in swine. Surg Endosc 2008;22:2117-22.

15. Woodward T, McCluskey D 3rd, Wallace MB, et al. Pilot study of transesophageal endoscopic surgery: NOTES esophagomyotomy, vagotomy, lymphadenectomy. J Laparoendosc Adv Surg Tech 2008;18:743-5.

16. Pauli EM, Mathew A, Haluck RS, et al. Technique for transesophageal endoscopic cardiomyotomy (Heller myotomy): video presentation at the Society of American Gastrointestinal and Endoscopic Surgeons (SAGES). Surg Endosc 2008;22:2279-80.

17. Fritscher-Ravens A, Cuming $T$, Jacobsen B, et al. Feasibility and safety of endoscopic full-thickness esophageal wall resection and defect closure: a prospective long-term survival animal study. Gastrointest Endosc 2009;69:1314-20.

18. Turner BG, Gee DW, Cizginer S, et al. Feasibility of endoscopic transesophageal thoracic sympathectomy. Gastrointest Endosc 2010;71: 171-5.

19. Fritscher-Ravens A, Ganbari A, Mosse CA, et al. Transesophageal endoscopic ultrasound-guided access to the heart. Endoscopy 2007;39: 385-9.

20. Rolanda C, Silva D, Branco C, et al. Peroral esophageal segmentectomy and anastomosis with single transthoracic trocar assistance: a step forward in thoracic NOTES. Endoscopy 2011;43:14-20.

21. Block PC, Burstein S, Casale PN, et al. Percutaneous left atrial appendage occlusion for patients in atrial fibrillation suboptimal for warfarin therapy: 5-year results of the PLAATO (Percutaneous Left Atrial Appendage Transcatheter Occlusion) Study. JACC Cardiovasc Interv 2009;2:594600.

22. Holmes DR, Reddy VY, Turi ZG, et al; PROTECT AF Investigators. Percutaneous closure of the left atrial appendage versus warfarin therapy for prevention of stroke in patients with atrial fibrillation: a randomised non-inferiority trial. Lancet 2009;374:534-42.

23. Cruz-Gonzalez I, Moreiras JM, García E. Thrombus formation after left atrial appendage exclusion using an Amplatzer cardiac plug device. Catheter Cardiovasc Interv. Epub 2011 Apr 26.

24. Bartus K, Bednarek J, Myc J, et al. Feasibility of closed-chest ligation of the left atrial appendage in humans. Heart Rhythm 2011;8:188-93.

25. Katz ES, Tsiamtsiouris T, Applebaum RM, et al. Surgical left atrial appendage ligation is frequently incomplete: a transesophageal echocardiographic study. J Am Coll Cardiol 2000;36:468-71.

26. Walsh SR, Cousins C, Tang TY, et al. lonizing radiation in endovascular interventions. J Endovasc Ther 2008;15:680-7.

27. Yilmaz A, Geuzebroek GS, Van Putte BP, et al. Completely thoracoscopic pulmonary vein isolation with ganglionic plexus ablation and left atrial appendage amputation for treatment of atrial fibrillation. Eur J Cardiothorac Surg 2010;38:356-60. 